\title{
Kinetic Study on Decolouration Process of Chelated Photomerocyanine of Spironaphthoxazine
}

\author{
Zhou Jinwei Tang Yingwu Zhao Fuqun Song Xinqi \\ (Department of Chemistry, Tsinghua University, Beijing 100084)
}

\section{Keywords: Photochromism, Spironaphthoxazine, Chelating, Decoloration, Mechanism}

Photochromism is a reversible transformation of a single chemical species between two states whose absorption spectra are recongnizably different, the transformation in at least one direction being induced by electromagnetic radiation ${ }^{[1]}$. Organic photochromic compounds have attracted more and more attentions, because colour change usually accompanied with the change of molecular properties and functions ${ }^{[2]}$. Spironaphthoxazines and their derivatives are photochromic compounds analogous to spiropyrans, which occur in reversible cleavage and rebinding in the (spiro) $\mathrm{C}-\mathrm{O}$ bond, and yield a color opening and a colorless closed form respectively ${ }^{[3]}$. In 1989, Tamaki et al. found that when there is a co-ordinating group such as $-\mathrm{OMe}^{-}-\mathrm{SO}_{3}^{-}$at the orthoposition of the $\mathrm{O}$ atom, the coloured open form can act as a chelating agent and form complexes with $\mathrm{M}$ (II) cations $^{[4]}$. With the formation of such complex, the coloured form can be stabilized and spectra may be different to unchelated one. In the recent work of Tamaki et al. [5], such a method has been used to stablized the coloured form of spironaphthoxazine in cetain polymer matrixes. In literatures more attention has been paid to the effect of the nature of metal ions on the formation of such complexes, no systematic work has been done on the mechanism of the decoloration process of the chelated form as well as the kinetic effect of metal ions on it. In this work, we report the chelatation of $\mathrm{Ni}\left(\mathrm{NO}_{3}\right)_{2}$, and 1,3, 3-trimethyl indole spironaphthoxazine with a coordinating group, 5-COOMe ( I ) in its open form (B). The concentration effect of $\mathrm{Ni}\left(\mathrm{NO}_{3}\right)_{2}$ on decoloration rate of the chelated complex was investigated by UV-VIS spectroscopic method.

The compounds(A) was prepared according to literature ${ }^{[3]}$. The irradiation was done with a $500 \mathrm{~W}$ high pressure $\mathrm{Hg}$ lamp and a suitable coloured glass filter. The absorption spectra and decolouration rates were measured with a diodes-array spectrophotometer(Hewlett Packard HP 8452)

The transformation of the coloured form of ( I ) in acetone solution is much faster than in ethanol, no reliable decoloration rate constant can be obtained with the steady

Received 1993-12-31, revised 1994-01-25. Correspodent: Zhou Jinwei. 
state methoed. When $\mathrm{Ni}\left(\mathrm{NO}_{3}\right)_{2}$ is added, the coloured form is stablized, and a slight shift of the $\lambda_{\max }$ can be observed. This originates from the chelation of opened form with $\mathrm{Ni}$ (II) ions. Fig. la is the visible spectra of $1.0 \times 10^{-4} \mathrm{~mol} \cdot \mathrm{L}^{-1}$ (I) with $3.0 \times 10^{-6} \mathrm{~mol} \cdot \mathrm{L}^{-1}$ $\mathrm{Ni}\left(\mathrm{NO}_{3}\right)_{2}$ in acetone at different time after $2 \mathrm{~min} \mathrm{UV}$ irradiation. From Fig.la it can be seen that the $\lambda_{\max }$ of the complex is about $606 \mathrm{~nm}$. The rate constant of thermal decoloration of the complex can be found by using equation ${ }^{[1]}$ :

$$
\ln \left(A_{t}-A_{e}\right)=-k_{1} t+C
$$

Where $A_{t}$ is the absorbance at the $\lambda_{\max }$ of the chelated opened form at time $t, A_{\mathrm{e}}$ is the equilibrium absorbance at the $\lambda_{\max }$ (taken as the absorbance after $2-6 \mathrm{~h}$ in the dark.)
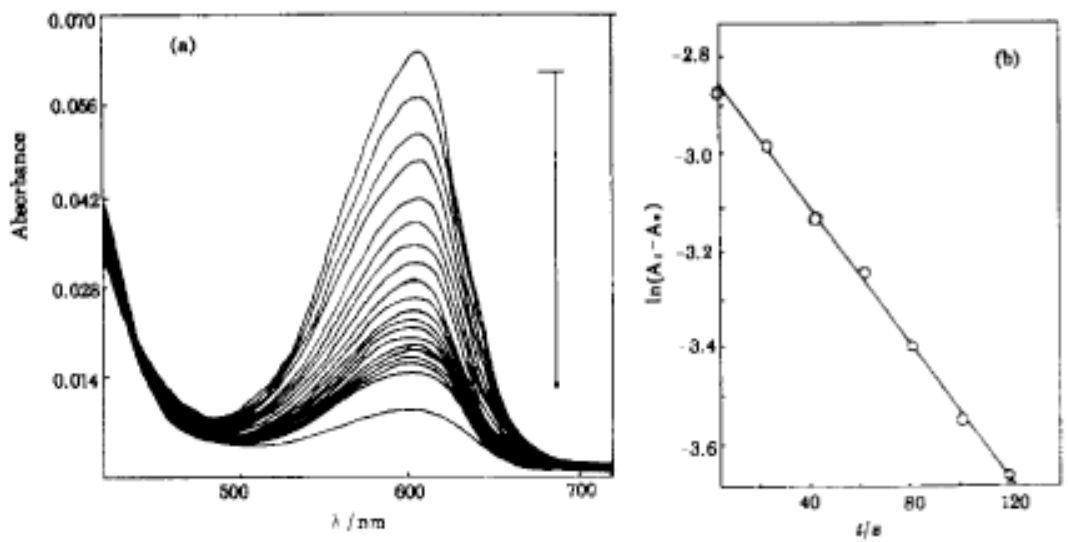

Fig.l (a) At $1.6 \mathrm{C}$, visible spectral changes of $1.0 \times 10^{-4} \mathrm{~mol} \cdot \mathrm{L}^{-1}(\mathrm{~A})$ with $3.0 \times 10^{-6} \mathrm{~mol} \cdot \mathrm{L}^{-1} \mathrm{Ni}\left(\mathrm{NO}_{3}\right)_{2}$ after $2 \mathrm{~min} \mathrm{UV}$ irradiation at different times(sec.): $0,20,40,60,80,100,120,140,160,180,200,220,240$, $260,280,300,320,340,360, \infty$ and unirradiated.

(b) first-order plot for the thermal decoloration of the chelate

Table 1 Correlation between the observed decoloration rates $\mathrm{k}_{\mathrm{ub}}$ with $\mathrm{Ni}\left(\mathrm{NO}_{3}\right)_{2}$ concentrations

$\begin{array}{ccccccc}{[\mathrm{Ni}(\mathrm{II})] \cdot 10^{6} \mathrm{~mol} \cdot \mathrm{L}^{-1}} & 3.0 & 5.0 & 8.0 & 10.0 & 16.0 & 20.0 \\ 1 /[\mathrm{N} \mathrm{i}(\mathrm{II})] \cdot 10^{-6} \mathrm{~mol} \cdot \mathrm{L}^{-1} & 33.3 & 20.0 & 12.5 & 10.0 & 6.25 & 5.00 \\ k_{\mathrm{ob}} \cdot 10^{3},\left(\mathrm{~s}^{-1}\right) & 6.60 & 4.17 & 2.48 & 2.11 & 1.37 & 1.05\end{array}$

Fig. 1b shows that the thermal decoloration kinetics fit eq.(1) very well. This indicates that the thermal decoloration is of first order to the chelate complex. The effect of $\mathrm{Ni}$ (II) concentrations on the decoloration rate in acetone solution, and the changes of the absorbance at $606 \mathrm{~nm}$ with time were recorded after irradiation. Fig.2a gives two examples, the concentrations of $\mathrm{Ni}\left(\mathrm{NO}_{3}\right)_{2}$ are of $1.0 \times 10^{-5} \mathrm{~mol} \cdot \mathrm{L}^{-1}$ and $2.0 \times 10^{-5} \mathrm{~mol} \cdot \mathrm{L}^{-1}$, respectively. From Fig.2a, the rate constant plot for first-order decoloration process can be obtained(Fig.2b). They were listed in Table 1.

Discussion and Conclusion The chelate formation process can be shown in scheme 1 . There are two possible routines for the transformantion of the chelate (C) to the colorless form (A). The first way is, the metal ion is dechelated and gives the metal free opened 
form (B) and then to (A); the other is that it changes directly from (C) to the original colourless (A).
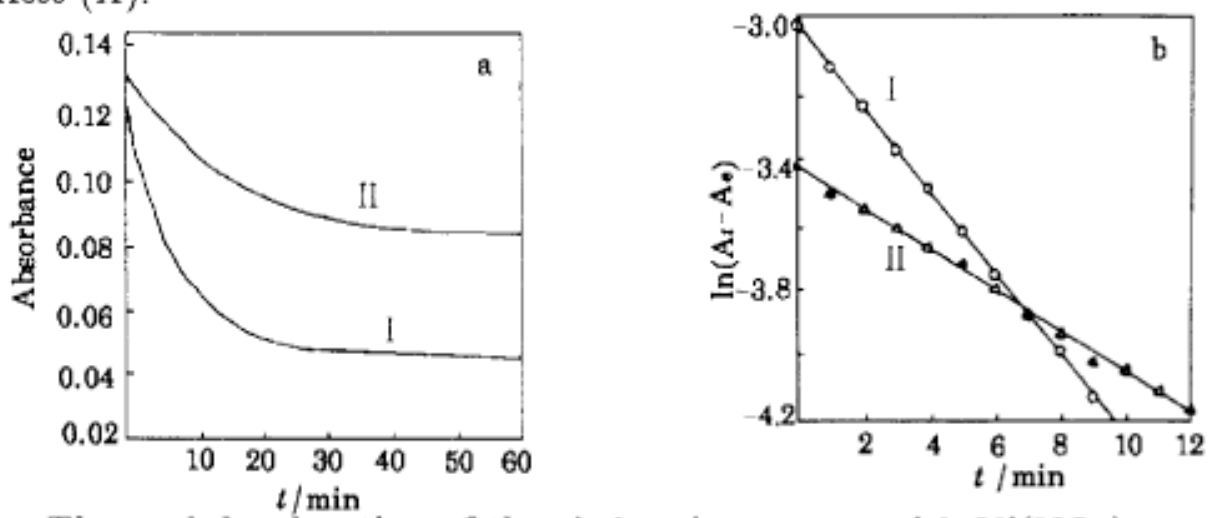

Fig.2 a: Thermal decoloration of the chelate in acetone with $\mathrm{Ni}\left(\mathrm{NO}_{3}\right)_{2}$ concentrations of $1.0 \times 10^{-5} \mathrm{~mol} \cdot \mathrm{L}^{-1}(\mathrm{I})$ and $2.0 \times 10^{-5} \mathrm{~mol} \cdot \mathrm{L}^{-1}($ I I ), respectively b: first-order plots for the thermal decoloration of the chelate. $\mathrm{Ni}\left(\mathrm{NO}_{3}\right)_{2}$ concentration: $1.0 \times 10^{-5} \mathrm{~mol} \cdot \mathrm{L}^{-1}$ ( I ), $\mathbf{2 . 0} \times 10^{-5} \mathrm{~mol} \cdot \mathrm{L}^{-1}$ (II)

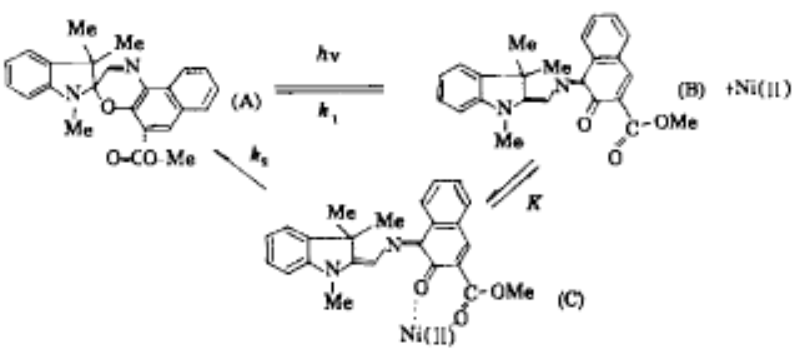

Scheme 1

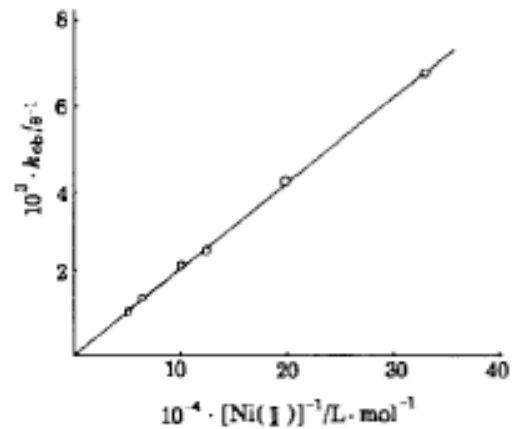

Fig.3 The variation of the observed decoloration rates $k_{\text {ob }}$ with the reciprocal of $\mathrm{Ni}$ (II) concetration

From scheme 1, we have

because

$$
\frac{-\mathrm{d}[\mathrm{C}]}{\mathrm{d} t}=\frac{\mathrm{d}[\mathrm{A}]}{\mathrm{d} t}=k_{1}[\mathrm{~B}]+k_{2}[\mathrm{C}]=\left(\frac{k_{1}}{K[\mathrm{Ni}(\mathrm{II})]}+k_{2}\right)[\mathrm{C}]
$$

then

$$
\begin{aligned}
& -\frac{\mathrm{d}[\mathrm{C}]}{\mathrm{dt}}=k_{\mathrm{ob}}[C] \\
k_{\mathrm{Ob}} & =\frac{k_{1}}{K[\mathrm{Ni}(\mathrm{II})]}+k_{2}
\end{aligned}
$$

$k_{\mathrm{ob}}$ : the observed decoloration rate constant of $\mathrm{C} ; k_{1}$ : the decoloration rate constant of $\mathrm{B}$; $K$ : the equilibrium constant of the chelated complex.

Fig.3 was obtained by treating experimental data with equation (4). It can be seen that $k_{2}=0, k_{1} / K=2.0 \times 10^{-8}$, this shows that the chelate complex can not be decolorated to the colourless form directly, then $k_{\mathrm{ob}} \propto 1 /[\mathrm{Ni}(\mathrm{II})]$. This indicates that routine 1 is the key decoloration path and routine 2 may be negligible under our experimental conditions. Therefore we can adjust the decorolate rate by controlling the concentration of $\mathrm{Ni}(\mathrm{II})$. 


\section{References}

1 Dürr H. Angew, Chem. Int. Ed. Engl., 1989, 28:413

2 Dürr H. Bouas-Laurent H. ed., Photochromism, Molecular and Systems. Chp. 8, Elsevier, Amsterdam, 1990

3 Dürr H. Bouas-Laurent H. ed., Photochromism, Molecular and Systems. Chp. 10, Elsevier, Amsterdam, 1990

4 Tamaki T, Ichimura K. J. Chem. Soc. Chem. Commun., 1989: 1477

5 Tamaki T, Kawanishi Y, Seki T, et al., J. Photopolym. Sci. Technol., 1990, 3(1):85

6 Drummond C J, Furlong D N. J. Chem. Soc. Faraday Trans., 1990, 86(21):3613

\section{光致变色螺菜并恶嗪配合物的根色过程动力学研究}

周金韧唐应武赵福群宋心琦

(清华大学化学系, 北京 100084)

摘要 报导了一种带 $5^{\prime}-\mathrm{CO}_{2} \mathrm{Me}$ 取代基的㛊恶噒 (A) 的开环形式 (B) 与金禹禹子的配合 作用. 利用柴外可见吸收光橧研究了金禹禹子浓度的殿响, 并证明了有色体配合物 (C) 的 主要消色过程是先解禹出金禹禹子生成 (B). 再褯色生成闭环无色体 (A). 未观测到由 (C) 直接褯色生成 (A) 的过程.

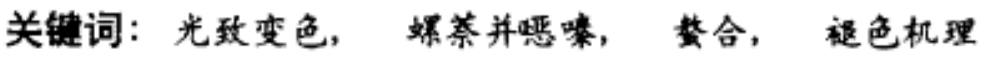

